\title{
Lysobacter capsici AZ78 produces cyclo(L-Pro-L-Tyr), a 2,5-diketopiperazine with toxic activity against sporangia of Phytophthora infestans and Plasmopara viticola
}

\author{
G. Puopolo ${ }^{1}$, A. Cimmino ${ }^{2}$, M.C. Palmieri ${ }^{1}$, O. Giovannini ${ }^{1}$, A. Evidente ${ }^{2}$ and I. Pertot ${ }^{1}$ \\ 1 Department of Sustainable Agro-Ecosystems and Bioresources, Research and Innovation Centre, Fondazione Edmund Mach (FEM), S. Michele \\ all'Adige (TN), Italy \\ 2 Dipartimento di Scienze Chimiche, Università degli Studi di Napoli 'Federico II', Napoli, Italy
}

\section{Keywords}

anti-oomycete activity, cyclo(L-Pro-L-Tyr), Lysobacter capsici, Phytophthora infestans, Plasmopara viticola.

\section{Correspondence \\ Gerardo Puopolo, Department of Sustainable Agro-Ecosystems and Bioresources, Research and Innovation Centre, Fondazione Edmund Mach (FEM), 38010 S. Michele all'Adige (TN), Italy. \\ E-mail: gerardo.puopolo@fmach.it}

2014/0840: received 23 April 2014, revised 10 July 2014 and accepted 24 July 2014

doi:10.1111/jam.12611

\begin{abstract}
Aims: To investigate low molecular weight compounds produced in vitro by Lysobacter capsici AZ78 and their toxic activity against sporangia of plant pathogenic oomycetes.

Methods and Results: Assays carried out in vitro showed that L. capsici AZ78 drastically inhibits the growth of plant pathogenic oomycetes. Accordingly, the preventive application of culture filtrates of L. capsici AZ78 on grapevine and tomato plants reduced the infections, respectively, caused by Plasmopara ( $P l$.) viticola and Phytophthora infestans. The subsequent chemical analysis of the culture filtrates of L. capsici AZ78 by spectroscopic (essentially 1D and $2 \mathrm{D}{ }^{1} \mathrm{H}$ NMR and ${ }^{13} \mathrm{C}$ NMR and ESI MS spectra) and optical methods led to the identification of the 2,5-diketopiperazine cyclo(L-Pro-L-Tyr) that inhibited the development of $P$. infestans sporangia in vitro and on tomato leaves. Furthermore, a genomic region with high sequence identity with genes coding for a hybrid polyketide synthase and nonribosomal peptide synthetase was detected in L. capsici AZ78.

Conclusions: Lysobacter capsici AZ78 produces cyclo(L-Pro-L-Tyr) in vitro that was effective in killing the sporangia of $P$. infestans and Pl. viticola in vitro. Moreover, this low molecular weight compound prevents the occurrence of late blight lesions when applied on tomato leaves.

Significance and Impact of the Study: The application of L. capsici AZ78 cells or its own culture filtrates effectively controls both P. infestans and Pl. viticola. Cyclo(L-Pro-L-Tyr) produced by L. capsici AZ78 is toxic against sporangia of both these oomycetes. These data enforce the potential in the use of Lysobacter members for the control of plant pathogenic oomycetes and provide the basis for the development of new low-impact fungicides based on cyclo(L-Pro-LTyr).
\end{abstract}

\section{Introduction}

A high number of destructive plant diseases are caused by plant pathogenic oomycetes. Phytophthora infestans Mont. (De Bary), the causal agent of late blight of potato (Solanum tuberosum) and tomato (Solanum lycopersicum), was responsible for instance for the epidemics that led to the Irish potato famine (Fry 2008). Another example of important plant diseases caused by oomycetes is downy mildew of grapevine (Vitis vinifera) caused by the obligate parasite Plasmopara (Pl.) viticola (Gessler et al. 2011). The control of both these plant pathogenic oomycetes relies mainly on intensive application of chemical fungicides and copper in conventional and organic agriculture, respectively (Fry and Goodwin 1997; Kato et al. 1997a; Gessler et al. 2011). Concerns about the negative 
impact of chemical fungicides and copper on the environment and human health are however increasing, and more environmental-friendly solutions are being increasingly demanded. The use of micro-organisms as active ingredients in plant protection products represents a sustainable alternative to synthetic substances. Microbial strains should however be carefully characterized before being applied as a biopesticide; thus, determining the secondary metabolic profile is crucial to the development of plant protection products.

There are at present few bacterial strains capable of controlling Pl. viticola (Tilcher et al. 1994, 2002), while bacteria, mainly belonging to the genera Bacillus and Pseudomonas (Ps.), have so far given the most interesting and promising results in controlling $P$. infestans on tomato plants (Yan et al. 2002; Kloepper et al. 2004; Tran et al. 2007; Halfeld-Vieira et al. 2008; Lamsal et al. 2013). Some of these strains indirectly reduce the attacks of $P$. infestans by triggering induced systemic resistance in tomato plants (Yan et al. 2002; Tran et al. 2007). Biological control bacteria may also be mixed to control tomato late blight, and the concurrent application of a rhizobacterial Bacillus cereus strain with epiphytic antagonists belonging to Cellulomonas flavigena, Candida sp. and Cryptococcus sp. produced a higher level of protection against $P$. infestans (Lourenço Júnior et al. 2006). Bacterial antagonists protect tomato plants also by acting directly on the zoospores and/or sporangia of $P$. infestans, as in the case of Pseudomonas fluorescens SS101 capable of killing $P$. infestans zoospores through biosynthesis of the cyclic lipopeptide massetolide A (Tran et al. 2007). Although several examples of biocontrol bacteria are reported in the literature, none of them has led to the development of a biofungicide that has been proved successful against these plant pathogenic oomycetes. There is therefore still a need to identify new bacterial strains to serve as active ingredients of low-impact biofungicides for use against $P$. infestans and Pl. viticola (Mizubuti et al. 2007; Gessler et al. 2011).

The bacterial genus Lysobacter (Christensen and Cook 1978) encompasses species that share several biological features that make them a suitable source of new biological control agents of plant diseases caused by plant pathogenic oomycetes (Hayward et al. 2010). For instance, Lysobacter enzymogenes strain $3.1 \mathrm{~T} 8$ is active against different plant pathogenic oomycetes by producing lytic enzymes, biosurfactants and anti-oomycete compounds (Folman et al. 2001, 2003, 2004). The application of Lysobacter sp. SB-K88 effectively controls the damping-off of sugar beet caused by Pythium spp. in soil (Homma et al. 1993; Nakayama et al. 1999). Recently, we showed that the prophylactic application of Lysobacter capsici AZ78 to grapevine leaves results in the drastic reduction of grapevine downy mildew caused by the plant pathogenic oomycete Pl. viticola (Puopolo et al. 2014). Furthermore, we also produced evidence that members of the Lysobacter antibioticus, L. capsici, L. enzymogenes and Lysobacter gummosus species are resistant to copper and this biological feature permits the combination of L. capsici AZ78 with a low dose of a copper-based fungicide for more effective control of grapevine downy mildew (Puopolo et al. 2014).

Building on our previous results, the current study aimed at investigating the secondary metabolites with anti-oomycete activity released in vitro by L. capsici AZ78. Our attention was focused on low molecular weight compounds synthesized by L. capsici AZ78, and we characterized in particular the direct activity of one of these against sporangia of $P$. infestans and $P l$. viticola.

\section{Materials and methods}

\section{Lysobacter capsici AZ78 and plant pathogenic oomycetes}

Lysobacter capsici AZ78 was stored at length in glycerol $40 \%$ at $-80^{\circ} \mathrm{C}$ and routinely grown on Luria-Bertani agar (LBA; Sigma-Aldrich, St. Louis, MO) in Petri dishes (90 $\mathrm{mm}$ diameter). To produce the culture filtrates, L. capsici AZ78 was grown in a modified LB medium [tryptone (Sigma-Aldrich) $10 \mathrm{~g} \mathrm{l}^{-1}$ and yeast extract (Sigma-Aldrich) $\left.5 \mathrm{~g} \mathrm{l}^{-1}\right)$ ]. Sodium chloride was not employed in modified LB medium so as to avoid any phytotoxic effects on plants.

Isolates of the plant pathogenic oomycetes Phytophthora cactorum, Phytophthora capsici, Phytophthora cinnamomi and Pythium (Py.) ultimum, from our laboratory culture collection, were stored in sterile tubes containing potato dextrose agar (PDA; Oxoid, Cambridge, $\mathrm{UK}$ ) and routinely grown on PDA plates at $22^{\circ} \mathrm{C}$. Phytophthora infestans provided by $\mathrm{M}$. Finckh and A. Butz (University of Kassel, Germany) was maintained on pea agar medium (PAM, 12.5\% frozen pea and 1.2\% agar in distilled water) at $17^{\circ} \mathrm{C}$ and stored at length in glycerol $20 \%$ at $-80^{\circ} \mathrm{C}$. The inoculum was prepared by collecting fresh sporangia from sporulating colonies developed after 21 days at $17^{\circ} \mathrm{C}$ on PAM (Sharma et al. 2010). Petri dishes were flooded with $5 \mathrm{ml}$ of cold $\left(4-5^{\circ} \mathrm{C}\right)$ distilled water, and sporangia were scraped using sterile spatulas and transferred into sterile 50-ml tubes. Plasmopara viticola was isolated from an untreated vineyard in S. Michele all'Adige (Italy) in 2013 and maintained on grapevine plants $(V$. vinifera $\mathrm{cv}$. Pinot Noir plants, grafted onto Kober $5 \mathrm{BB}$ ) by subsequent weekly inoculations. To obtain sporangia, grapevine plants showing oil spot symptoms were kept overnight in the dark at $20-21^{\circ} \mathrm{C}$ and $100 \% \mathrm{RH}$. The inoculum of $\mathrm{Pl}$. viticola was prepared 
by washing the freshly sporulating lesions on the abaxial leaf surface with cold $\left(4-5^{\circ} \mathrm{C}\right)$ distilled water. Unless otherwise stated, the sporangial suspensions of $P$. infestans and $\mathrm{Pl}$. viticola were then adjusted to a concentration of $2.5 \times 10^{5}$ sporangia $\mathrm{ml}^{-1}$ by counting with a haemocytometer (Thoma chamber; HBG, Giessen-Lützellindem, Germany) under a light microscope and used in all the experiments.

\section{Characterization of the activity spectrum of Lysobacter capsici AZ78 against plant pathogenic oomycetes in vitro}

To define the activity spectrum of $L$. capsici AZ78 against plant pathogenic oomycetes, its ability to inhibit the mycelial growth of five oomycetes was evaluated in dual culture on PDA (P. cactorum, P. capsici, P. cinnamomi and $P y$. ultimum) and PAM (P. infestans) dishes. Briefly, $20 \mu \mathrm{l}$ of a L. capsici AZ78 cell suspension $\left(1 \times 10^{8} \mathrm{CFU} \mathrm{m} \mathrm{m}^{-1}\right)$ was spotted on two opposite edges of dishes containing the above-mentioned growth media and kept at $27^{\circ} \mathrm{C}$ for $24 \mathrm{~h}$. After this incubation period, plugs of mycelium ( $5 \mathrm{~mm}$ diameter) were cut from the edge of the young oomycete colonies and placed at the centre of the dishes containing L. capsici AZ78 macrocolonies. PDA and PAM dishes seeded only with mycelium plugs were used as controls. Inhibition of mycelial growth was evaluated by scoring the oomycete colony diameters after 7 -day incubation at $20^{\circ} \mathrm{C}$. Each treatment was carried out on three dishes (replicates), and experiments were repeated.

\section{Assessment of the efficacy of culture filtrates of Lysobacter capsici AZ78 to control Phytophthora infestans and Plasmopara viticola in vivo}

In each experiment, L. capsici AZ78 cell suspensions and its own supernatants were prepared according to the following procedure. Bottles containing $500 \mathrm{ml}$ of modified LB medium were inoculated with $5 \mathrm{ml}$ of L. capsici AZ78 cell suspension $\left(1 \times 10^{8} \mathrm{CFU} \mathrm{ml}^{-1}\right)$ and incubated at $27^{\circ} \mathrm{C}$ for $72 \mathrm{~h}$ on a rotary shaker at $200 \mathrm{rev} \mathrm{min}^{-1}$. At the end of this period, the content of the flasks was centrifuged at $4300 \mathrm{~g}$ for $20 \mathrm{~min}$, and the supernatants were filter-sterilized $(0.22 \mu \mathrm{m}$; Sigma-Aldrich) and collected in sterile 1-1 bottles. Pelleted cells were resuspended in sterile distilled water to a final optical density at $600 \mathrm{~nm}$ of $0 \cdot 1$ corresponding to $\approx 1 \times 10^{8} \mathrm{CFU} \mathrm{ml} \mathrm{m}^{-1}$.

The bioassays for the evaluation of the ability of L. capsici AZ78 and its own culture filtrates to control $P$. infestans and $P l$. viticola were, respectively, carried out on tomato (S. lycopersicum cv. Tondo Rosso) and on grapevine plants. Two-year-old grapevine plants were grown in a greenhouse under controlled conditions $\left(20 \pm 0 \cdot 5^{\circ} \mathrm{C} ; 70 \pm 10 \%\right.$ relative humidity, $\mathrm{RH} ; 16$-h photoperiod) in 2.5-1 pots containing a mixture of peat and pumice $(3: 1)$ until the plants had produced two shoots with at least nine leaves each. Pregerminated tomato seeds were sown on sterile peat (autoclaved twice for $20 \mathrm{~min}$ at $120^{\circ} \mathrm{C}$ with an interval of $24 \mathrm{~h}$ ) in sterile 50 -ml pots maintained under greenhouse-controlled conditions $\left(25 \pm 1^{\circ} \mathrm{C} ; 70 \pm 10 \% \mathrm{RH} ; 16\right.$-h photoperiod $)$. Grapevine and tomato plants were ready for experimentation approximately 2 months after planting.

Lysobacter capsici AZ78 cells and its own culture filtrates were applied on grapevine and tomato plants $24 \mathrm{~h}$ before inoculation with $P l$. viticola and $P$. infestans, respectively. Treatments were applied on adaxial and abaxial leaf surfaces using a hand sprayer. Distilled water, modified LB medium and copper hydroxide (Kocide ${ }^{\circledR}$ 3000; Du Pont de Nemours, Wilmington, DE, $2.5 \mathrm{~g} \mathrm{l}^{-1}$ ) were used as controls and were applied $6 \mathrm{~h}$ before inoculation. Each grapevine and tomato plant was, respectively, sprayed with 40 and $20 \mathrm{ml}$ of each treatment preparation.

Tomato plants were artificially inoculated by spraying the entire plant with $P$. infestans sporangial suspensions. The plants were kept in the dark at $100 \% \mathrm{RH}$ and $18^{\circ} \mathrm{C}$ for $24 \mathrm{~h}$ and then transferred in a growth cabinet at $18^{\circ} \mathrm{C}$ at $80 \%$ RH with a 16/8-h day/night light regime. Plasmopara viticola inoculum was sprayed onto the abaxial surface of each fully expanded leaf using a hand sprayer. Once inoculated, grapevine plants were incubated at $20 \pm 0 \cdot 5^{\circ} \mathrm{C}(80-99 \% \mathrm{RH})$ in the dark for $24 \mathrm{~h}$, then maintained at $25^{\circ} \mathrm{C}(60-80 \% \mathrm{RH})$ with a $16 / 8$-h day/ night light regime. Seven days after inoculation, the plants were incubated overnight in the dark at $20 \pm 0 \cdot 5^{\circ} \mathrm{C}$ and $80-99 \% \mathrm{RH}$ to induce sporulation.

Each treatment was carried out on nine plants (replicates), and experiments were repeated. Seven days after pathogen inoculation, disease incidence (percentage of symptomatic leaves) and disease severity (percentage of leaf area showing symptoms) were visually assessed and expressed as percentages. The efficacy of treatments in reducing disease severity was calculated according to the following formula:

Plant protection efficacy $=[($ disease severity in untreated plants - disease severity in treated plants)/(disease severity in untreated plants) $] \times 100$.

The population of L. capsici AZ78 on grapevine and tomato leaves was assessed at the beginning and at the end of the greenhouse experiments using the dilution plating method according to Puopolo et al. (2014). 
Extraction and purification of metabolites from Lysobacter capsici AZ78 culture filtrates

The culture supernatants of L. capsici AZ78 produced in modified LB medium as described above were filtered and lyophilized. Subsequently, culture filtrates (3.0 l) were dissolved in $10^{-1}$ of initial volume with distilled water and extracted with EtOAc $(4 \times 300 \mathrm{ml})$. The organic extracts were combined, dried $\left(\mathrm{Na}_{2} \mathrm{SO}_{4}\right)$ and evaporated under reduced pressure to yield a brown solid residue $(261.5 \mathrm{mg})$. The residue was then submitted to bioassay-guided fractionation through column chromatography $(800 \times 25 \mathrm{~mm})$ on silica gel, eluted with the $\mathrm{CHCl}_{3}-i-\mathrm{PrOH}(9 / 1 \mathrm{v} / \mathrm{v})$ until $\mathrm{CHCl}_{3}-i-\mathrm{PrOH}(7 / 3 \mathrm{v} / \mathrm{v})$. One hundred and fifty tubes $(10 \mathrm{ml})$ were checked on thin-layer chromatography (TLC) and combined. Four homogenous chromatographic fraction groups were evaluated for their toxicity against sporangia of P. infestans and Pl. viticola, as described below, at a final concentration of $1 \mathrm{mg} \mathrm{ml}^{-1}$.

The residue $(56.5 \mathrm{mg})$ of the second chromatographic fraction group was further purified by TLC on silica gel and eluted with the $\mathrm{CHCl} 3-\mathrm{i}-\mathrm{PrOH}(8 / 2 \mathrm{v} / \mathrm{v})$, yielding a homogeneous anamorphous solid $\left[\begin{array}{lll}R_{f} & 0.69 & \text {, eluent }\end{array}\right.$ $\mathrm{CHCl} 3-\mathrm{i}-\mathrm{PrOH}(8 / 2 \mathrm{v} / \mathrm{v})]$.

Identification and characterization of Lysobacter capsici AZ78 low molecular weight secondary metabolites

Optical rotation was measured in $\mathrm{MeOH}$ on a polarimeter (Jasco, Easton, MD). IR spectra were recorded as deposit glass film on a Perkin-Elmer (Norwalk, CT) Spectrum. One FT-IR spectrometer and UV spectra were measured in $\mathrm{MeCN}$ on a Perkin-Elmer Lambda $23 \mathrm{UV} /$ vis spectrophotometer. ${ }^{1} \mathrm{H} \mathrm{NMR}$ and ${ }^{13} \mathrm{C}$ NMR spectra were recorded at 600 or 400 and 125 or $100 \mathrm{MHz}$, respectively, in $\mathrm{CDCl}_{3}$, on spectrometers (Bruker, Leipzig, Germany). The same solvent was used as internal standard. Carbon multiplicities were determined by distortionless enhancement by polarization transfer (DEPT) spectra (Berger and Braun 2004). DEPT, correlation spectroscopy (COSY-45), heteronuclear single-quantum coherence (HSQC), heteronuclear multiple-bond correlation (HMBC) and nuclear overhauser enhancement spectroscopy (NOESY) experiments were performed using standard Bruker microprograms (Berger and Braun 2004). High-resolution (HR) and electrospray ionization mass spectroscopy (ESIMS) spectra were recorded on Thermo LTQ Velos (Thermo Fisher Scientific, Bremen, Germany) and 6120 Quadrupole LC/MS (Agilent Technologies, Santa Clara, CA), respectively. Analytical and preparative TLC was performed on silica gel [Kieselgel 60, $\mathrm{F}_{254}, \quad 0.25$ and $0.5 \mathrm{~mm}$ (Merck, Darmstadt,
Germany)] dishes. The spots were visualized by exposure to UV light at $254 \mathrm{~nm}$, iodine vapours, or by spraying first with $10 \% \mathrm{H}_{2} \mathrm{SO}_{4}$ in $\mathrm{MeOH}$ and then with $5 \%$ phosphomolybdic acid in $\mathrm{EtOH}$, followed by heating at $110^{\circ} \mathrm{C}$ for $10 \mathrm{~min}$. Column chromatography was performed on a Kieselgel 60, 0.063-0.200 mm silica gel column (Merck).

Evaluation of the anti-oomycete activity against Phytophthora infestans and Plasmopara viticola sporangia of Lysobacter capsici AZ78 secondary metabolites

Fifty microlitres of each chromatographic fraction group was added to $50 \mu \mathrm{l}$ of freshly prepared P. infestans or $P l$. viticola sporangia $\left(2 \times 10^{6}\right.$ sporangia $\left.\mathrm{ml}^{-1}\right)$ in sterile $1 \cdot 5-\mathrm{ml}$ tubes. The mixtures were then incubated for $60 \mathrm{~min}$ at $17^{\circ} \mathrm{C}$ and then stained for $5 \mathrm{~min}$ with a combination of 5,6-carboxyfluorescein diacetate (SigmaAldrich; 0.01\%) in DMSO (Sigma-Aldrich; 0.01\%) and propidium iodide (Sigma-Aldrich; $100 \mu \mathrm{g} \mathrm{ml}^{-1}$ ), protocol adapted from Sergeeva et al. (2002) and Trouvelot et al. (2008). DMSO (0.01\%) and sterile distilled water were used as controls.

After the incubation period, the suspensions were transferred on glass slides (Fast-Read 102; Biosigma F, Cona, Italy) and observed under microscope Leica LMD7000 (Leica, Wetzlar, Germany) using the B/G/R filter (excitation filter: BP 550-590 nm; dichromatic mirror: $590 \mathrm{~nm}$; suppression filter: BP 600-680 nm) to count dead sporangia (emitting propidium iodide-dependent red fluorescence) and H3 filter (excitation filter: BP 420$490 \mathrm{~nm}$; dichromatic mirror: $510 \mathrm{~nm}$; suppression filter: LP $515 \mathrm{~nm}$ ) to count viable sporangia (emitting 5,6-carboxyfluorescein diacetate-dependent green fluorescence) (Trouvelot et al. 2008).

Each experiment involved three replicates (three $1 \cdot 5-\mathrm{ml}$ tubes), and a minimum of 100 sporangia was counted each time (five repetitions) according to Trouvelot et al. (2008). Three independent experiments were carried out.

\section{Confirmation of anti-oomycete activity of cyclo (L-Pro-L-Tyr) on Phytophthora infestans sporangia in vivo}

The anti-oomycete activity of cyclo(L-Pro-L-Tyr) was confirmed on $P$. infestans sporangia on detached tomato leaves according to Tran et al. (2007) with modifications. Purified cyclo(L-Pro-L-Tyr) isolated from L. capsici AZ78 culture filtrates was sprayed onto leaves collected from tomato plants ( 2 months old). The metabolite was sprayed at the following concentration: 10, 25, 50, 75 and $100 \mu \mathrm{g} \mathrm{ml}^{-1}$. Additional detached tomato leaves were treated with the 
L. capsici AZ78 cell-free culture filtrates. Leaves were maintained at room temperature for $1 \mathrm{~h}$ under laminar flow to dry. Subsequently, leaves were transferred in 90-mm Petri dishes (one leaf each dish) on sterile wet filter paper, and the abaxial part was inoculated with three drops $(10 \mu \mathrm{l})$ of a $P$. infestans sporangia suspension $\left(2 \times 10^{3}\right.$ sporangia $\mathrm{ml}^{-1}$ ) on each side of the leaf's midvein (six drops per leaf). Once inoculated, Petri dishes were allowed to dry under laminar flow for $20 \mathrm{~min}$ and then were placed in an incubator at $18^{\circ} \mathrm{C}$. Tomato leaves treated with sterile distilled water, DMSO (0.01\%) and copper hydroxide were used as controls. Four days after sporangial inoculation, disease incidence was assessed by scoring the occurrence of late blight lesions developed from the sporangial droplets. Each treatment was composed of five replicates (leaves), and the experiment was repeated.

At the end of the experiments, the occurrence of $L$. capsici AZ78 cells on detached tomato leaves was assessed using the dilution plating method as described above.

\section{Determination of a gene coding for polyketide synthase in Lysobacter capsici AZ78}

The genomic DNA of L. capsici AZ78 was extracted with a Genomic DNA isolation Kit (Qiagen, Holden, Germany) and used as the template in PCRs aimed at detecting the presence of gene coding for a polyketide synthase. The primer pair AZ78_pks1 F (5'-GGT TCC TCA AGC AGC TCA A-3')/AZ78_pks1 R (5'-GGA ACA GGT CGG TGT TGT A-3') was designed based on the nucleotide sequence from L. enzymogenes C3 coding for a hybrid polyketide synthase and nonribosomal peptide synthetase (GenBank Accession No. EF028635.2). In these PCRs, $2 \mu \mathrm{l}$ of genomic DNA was used as template in $25-\mu \mathrm{l}$ reaction including 1X Dream Taq Green PCR Mastermix (Thermo Fisher Scientific) and $0.2 \mu \mathrm{mol} \mathrm{l}^{-1}$ of primer AZ78_pks1 F/AZ78_pks1R. These PCRs involved a first cycle at $94^{\circ} \mathrm{C}$ for $3 \mathrm{~min}$ followed by 35 cycles of $94^{\circ} \mathrm{C}$ for $1 \mathrm{~min}, 57^{\circ} \mathrm{C}$ for $1 \mathrm{~min}$ and $72^{\circ} \mathrm{C}$ for $1 \mathrm{~min}$ with a final extension step at $72^{\circ} \mathrm{C}$ for $5 \mathrm{~min}$.

PCR products were purified using Exo-Sap (Euroclone S.p.a., Italy) according to manufacturer's instructions. Purified DNA amplicons were sequenced using BigDye Terminator v 3.1 (Thermo Fisher Scientific), and the resulting nucleotide sequences were analysed using BLASTN to find homologies with DNA sequences already deposited in GenBank. The most similar nucleotide sequences were collected from GenBank and used for phylogenetic analyses. All the sequences were aligned with CLUSTAL $\mathrm{x}$ (Thompson et al. 1997), and the alignment profile was then used to establish the evolutionary distances by applying Kimura's two-parameter model (Kimura 1983) implemented in the MEGA3 program (Kumar et al. 2004).
The same software was used to construct the best phylogenetic tree with the neighbour-joining method (Saitou and Nei 1987). Bootstrap analysis with 1000 replicates was performed to assess confidence levels for the branches (Felsenstein 1985).

\section{Statistical analyses}

The data attained in all the experiments were subjected to a two-way ANOva. If no significant differences were found, the data were pooled. In the case of data coming from dual-plate method, differences between mean values of oomycete colony diameters were statistically analysed by Student's $t$-test $(\alpha=0.05)$. In all the other cases, the data were arcsine-transformed prior to the two-way ANOVA and then analysed by ANOVA and mean comparisons were performed with a Tukey's test $(\alpha=0 \cdot 05)$. The data of plant protection efficacy were also checked for normality (Kolmogorov-Smirnov's test) and homoscedasticity (Bartlett's test) before ANOVA. All the statistical analysis was carried out using STATISTICA software 7.0 (Statsoft, Tulsa, OK).

\section{Results}

Characterization of the activity spectrum of Lysobacter capsici AZ78 against plant pathogenic oomycetes in vitro

The ability of L. capsici AZ78 to inhibit mycelial growth of some plant pathogenic oomycetes in vitro was chosen as first step in the investigation on the mechanisms involved in the antagonism aptitude of this bacterial strain. Lysobacter capsici AZ78 was able to inhibit the mycelial growth of the five plant pathogenic oomycetes tested (Fig. 1), and particularly, Phytophthora infestans growth was drastically impaired in the presence of the bacterium ( $\approx 73 \%$ inhibition).

\section{Assessment of the efficacy of culture filtrates of Lysobacter capsici AZ78 to control Phytophthora infestans and Plasmopara viticola in vivo}

Based on the strong pathogen inhibition recorded in the dual-culture test, we hypothesized that L. capsici AZ78 releases secondary metabolites with anti-oomycete activity in the medium. To validate this hypothesis and identify the active molecules, we assessed the efficacy of the culture filtrates of L. capsici AZ78 for the control of two selected oomycetes $P$. infestans and $\mathrm{Pl}$. viticola on tomato and grapevine plants, respectively. No statistical differences were recorded between the level of disease severity of the grapevine $(28 \pm 6$ and $24 \pm 3)$ and tomato $(58 \pm 12$ and $46 \pm 14)$ plants, respectively, treated with 
Figure 1 Mycelial growth of plant pathogenic oomycetes in dual culture by Lysobacter capsici AZ78. The black and grey histograms refer to the growth of the oomycetes in the presence of and in the absence of L. capsici AZ78. Oomycete colony diameters were scored after 7 days of incubation at $20^{\circ} \mathrm{C}$. Three dishes were used for each treatment, and data originating from two independent experiments were pooled. *Values differ significantly according to Student's $t$-test $(\alpha=0.05)$.

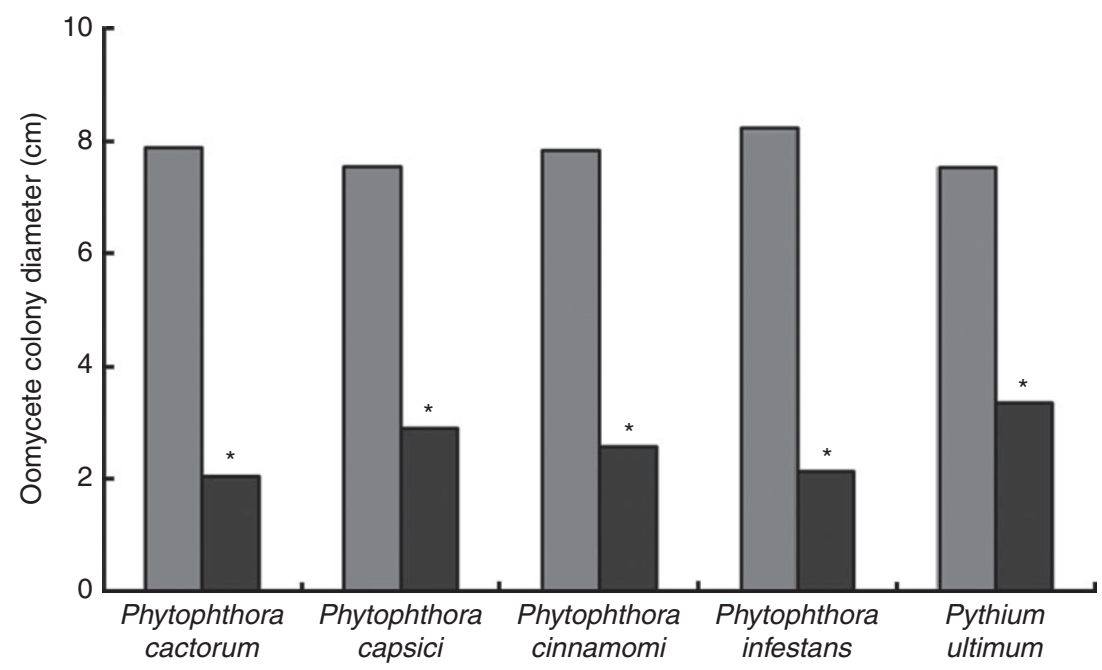

distilled water and modified LB medium. The plant protection efficacy of L. capsici AZ78 cells on tomato leaves did not significantly differ from that achieved with copper hydroxide with values close to $100 \%$ (Fig. 2a). The application of L. capsici AZ78 culture filtrates resulted in a plant protection efficacy of $74 \%$ (Fig. 2a), higher than the values achieved using modified LB (15.1\%, Fig. 2a). Similar results were obtained against $P l$. viticola on grapevine. In this case, plant protection efficacy of $L$. capsici AZ78 culture filtrates was $66.2 \%$ and lower than that achieved on plants treated with L. capsici AZ78 cells (92.4 $\%)$ and the copper hydroxide (90.7\%) (Fig. 2b). Additionally, the application of L. capsici AZ78 culture filtrates resulted also in a reduction of the incidence of symptomatic leaves, but the values were not significantly different from plants treated with distilled water or modified LB medium (Table S1). On the other hand, application of L. capsici AZ78 cells in both the pathosystems determined a drastic reduction of disease incidence similar to that achieved with copper treatments (Table S1). Lysobacter capsici AZ78 cells were never isolated from leaves collected from plants treated with distilled water, modified LB medium, AZ78 culture filtrates and copper-based fungicide, either at the beginning or at the end of the greenhouse trials. Lysobacter capsici AZ78 was recovered only from plants treated with L. capsici AZ78 cells. At the beginning of the trial, the population recovered from tomato leaves was $6.56 \pm 0.16 \log _{10} \mathrm{CFU} \mathrm{g} \mathrm{g}^{-1}$ of tomato leaf, while at the end of trial, population reached $5.01 \pm 0.02 \log _{10} \mathrm{CFU} \mathrm{g}^{-1}$ of tomato leaf. A similar population size was recorded on grapevine leaves at the beginning and at the end of the trials $(5 \cdot 16 \pm 0.12$ and $5 \cdot 18 \pm 0 \cdot 14 \log _{10} \mathrm{CFU} \mathrm{g}^{-1}$ of grapevine leaf, respectively).
Lysobacter capsici AZ78 produces cyclo(L-Pro-L-Tyr) a 2,5-diketopiperazine toxic against Phytophthora infestans and Plasmopara viticola sporangia

The fact that L. capsici AZ78 culture filtrates reduced the disease in both pathosystems prompted us to investigate the low molecular weight secondary metabolites with anti-oomycete activity produced by L. capsici AZ78 during its growth in modified LB medium. For this purpose, the liquid culture filtrates of L. capsici AZ78 were exhaustively extracted with ethyl acetate and the organic extract, showing high toxic activity against $P$. infestans and Pl. viticola sporangia (data not shown), was fractionated by column chromatography in four fractions (named Fraction A, B, C and D) that were then assessed for their capacity to kill sporangia of both the plant pathogenic oomycetes.

After $60 \mathrm{~min}$ of incubation in different solutions, both water- and DMSO (0.01\%)-treated sporangia of $P$. infestans and Pl. viticola (control samples) showed an $80 \%$ viability (Fig. S1a,b). The incubation in Fraction A and B caused, respectively, a decrease to 49 and $34 \%$ of sporangial viability in $P$. infestans (Fig. S1a) while a viability decrease to $19 \%$ was found in the case of Pl. viticola (Fig. S1b). On the other hand, Fraction C and D showed a limited negative effect on Pl. viticola sporangial viability and almost no effect on $P$. infestans (Fig. S1a,b).

The residue $(56.5 \mathrm{mg})$ of Fraction B was further purified by TLC yielding a homogeneous anamorphous solid (30.0 mg, corresponding to $10 \mu \mathrm{g} \mathrm{ml}^{-1}$ ). The anamorphous compound was identified as a cyclo(L-Pro-L-Tyr) (Fig. 3a), a $(3 S, 8 \mathrm{a} S)$ pyrrolo[1,2-a]pyrazine-1,4-dione, hexahydro-3-[(4-hydroxyphenyl)methyl], by comparing its spectroscopic (IR, UV, ${ }^{1} \mathrm{H}$; Fig. 3b) and ${ }^{13} \mathrm{C}$ NMR 

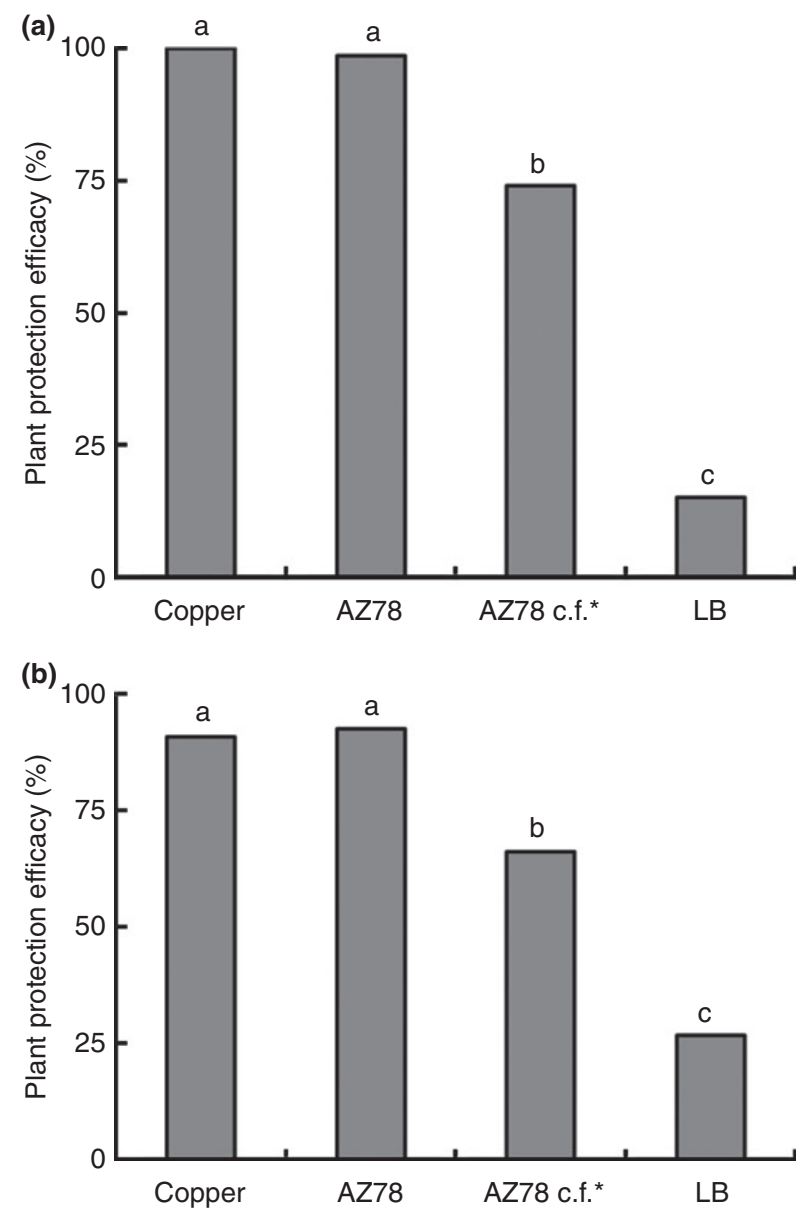

Figure 2 Plant protection efficacy against Phytophthora infestans (a) and Plasmopara viticola (b) achieved by the application of Lysobacter capsici AZ78 cells and its culture filtrates (c.f.*). Plant protection efficacy is expressed as (disease severity in untreated plants - disease severity in treated plants)/(disease severity in untreated plants) $\times 100$. Each treatment was applied on five plants (replicates), experiments were repeated, and data were pooled. Histograms with the same letters are not significantly different according to Tukey's test $(\alpha=0.05)$

(Fig. S2) and optical properties with those already reported in the literature (all the chemical characteristics are reported in Supporting information). The identification of cyclo(L-Pro-L-Tyr) was also confirmed by the couplings observed in the COSY and HSQC spectra (Figs S3 and S4) and by the correlation recorded in the NOESY spectrum (Fig. S5). Furthermore, the structure was supported by the several long-range coupling observed in the HMBC spectrum (Fig. S6) and by the data of its HRESI MS spectrum, which showed the dimeric sodiated $[2 \mathrm{M}+\mathrm{Na}]^{+}$and protonated $[2 \mathrm{M}+\mathrm{H}]^{+}$form, the sodium cluster $[\mathrm{M}+\mathrm{Na}]^{+}$and the pseudomolecular ion $[\mathrm{M}+\mathrm{H}]^{+}$ at $\mathrm{m} / \mathrm{z} 543.2217,521.2397,283.1051$ and 261.1231, respectively (Fig. S7). The absolute configuration to cyclo
(L-Pro-L-Tyr) was assigned by comparing its specific optical rotatory power with that reported in the literature.

\section{Confirmation of anti-oomycete activity of cyclo (L-Pro-L-Tyr) on Phytophthora infestans sporangia}

The anti-oomycete activity cyclo(L-Pro-L-Tyr) was confirmed in a bioassay carried out on detached tomato leaves. Lysobacter capsici AZ78 culture filtrates reduced $P$. infestans disease incidence $(10 \cdot 25 \pm 5 \cdot 27 \%)$ similar to copper hydroxide $(7 \cdot 00 \pm 4.99 \%$, Fig. 4$)$. A reduction in disease severity, although lower than L. capsici AZ78 culture filtrates, was observed with cyclo(L-Pro-L-Tyr) applied at concentrations ranging from 10 to $100 \mu \mathrm{g} \mathrm{ml}^{-1}$ (Fig. 4), and a clear dose effect of cyclo (L-Pro-L-Tyr) was recorded (Fig. S8). In more detail, the maximum level of protection was achieved by applying the cyclo(L-Pro-L-Tyr) at $100 \mu \mathrm{g} \mathrm{ml}^{-1}(26.67 \pm 4.21 \%)$ while the lowest concentrated solution determined a reduced protective effect $(66.67 \pm 4.71)$ that, however, was statistically lower than the disease incidence observed on leaves treated with sterile distilled water and DMSO (0.01\%, Fig. 4). At the end of the experiments, no L. capsici AZ78 cells were detected in any of the detached tomato leaves through dilution plating method.

\section{Detection of a gene coding for polyketide synthase in} Lysobacter capsici AZ78

A nucleotide region showing high sequence identity with polyketide synthase was detected in L. capsici AZ78. A DNA fragment of 1132 bp was amplified using the primer pair AZ78_PKS1 F/R specific for a nucleotide region coding for a hybrid polyketide synthase and nonribosomal peptide synthetase of L. enzymogenes C3. The resulting nucleotide sequence (GenBank accession no. KF841351) showed the highest sequence identity with the gene coding for polyketide synthase from L. capsici C3 (Fig. 5). The nucleotide region obtained from L. capsici AZ78 also shared high sequence identity with other bacterial strains such as Salinispora arenicola CNS-205 and others of different Streptomyces species (Fig. 5).

\section{Discussion}

Finding sustainable alternatives to chemical fungicides against destructive diseases caused by plant pathogenic oomycetes, such as late blight and grapevine downy mildew, is a priority for the future. Microbial biocontrol agents already offered a valid alternative in different pathosystems (Raaijmakers and Mazzola 2012), and Lysobacter genus could be a promising source for new active ingredients in biological plant protection products. 


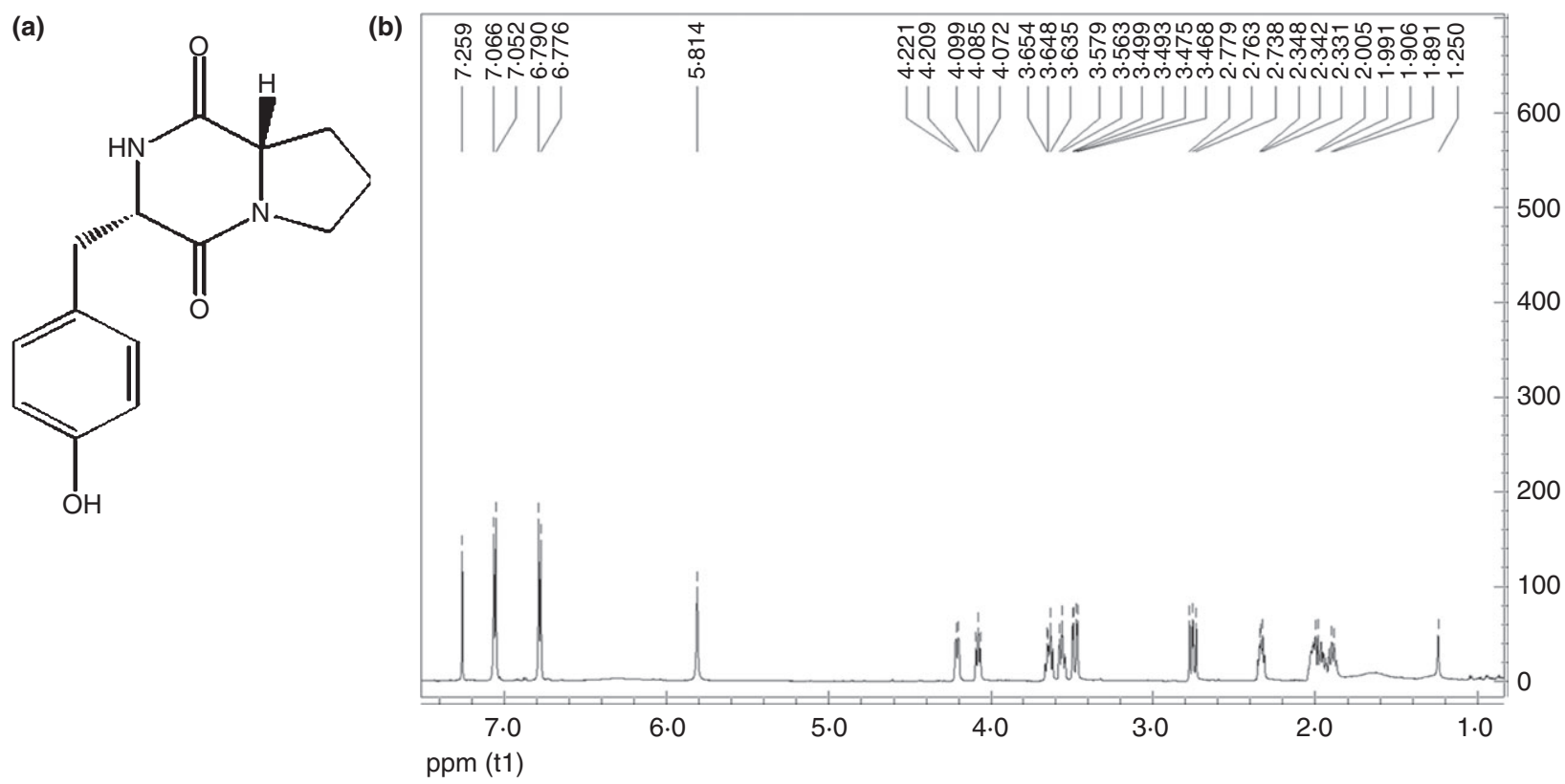

Figure 3 Identification of cyclo(L-Pro-L-Tyr) a 2,5-diketopiperazine produced by Lysobacter capsici AZ78. (a) Structural formula of cyclo(L-Pro-LTyr); (b) ${ }^{1} \mathrm{H}$ nuclear magnetic resonance (NMR) spectrum of cyclo(L-Pro-L-Tyr) was recorded at $600 \mathrm{MHz}$ in monodeuterated chloroform (CDCl ${ }_{3}$ ).

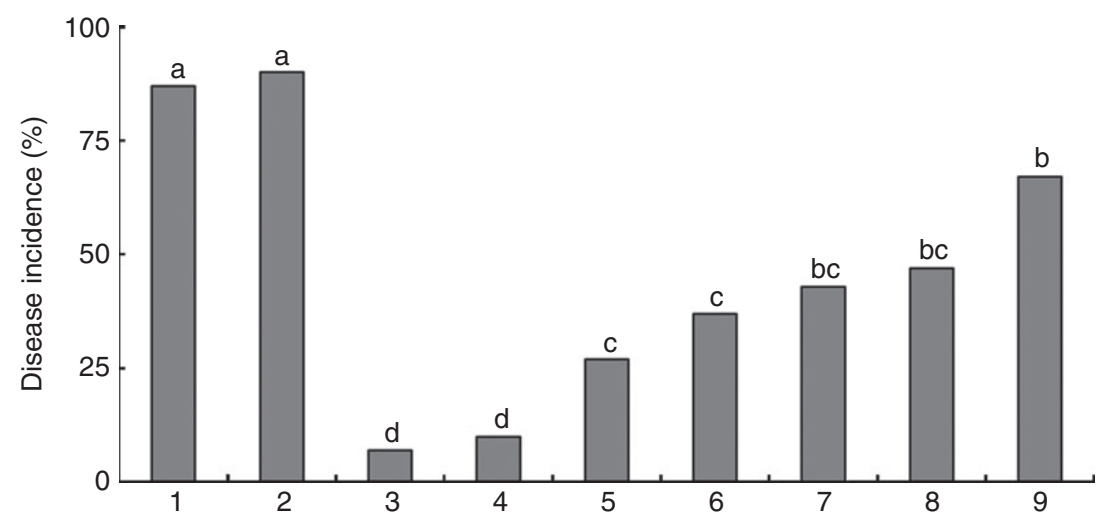

Figure 4 Capability of cyclo(L-Pro-L-Tyr) to protect detached tomato leaves against Phytophthora infestans attacks. The protective effect was evaluated by monitoring the disease incidence that is expressed as the percentage of late blight lesions developed from sporangial droplets. Five tomato leaves were used for each treatment, and experiments were repeated. Histograms with the same letters are not significantly different according to Tukey's test $(\alpha=0.05)$. (1) Sterile distilled water; (2) DMSO $0.01 \%$; (3) copper hydroxide; (5,6,7,8 and 9) cyclo(L-Pro-L-Tyr) at 100, $75,50,25$ and $10 \mu \mathrm{g} \mathrm{ml}^{-1}$.

We previously showed that L. capsici AZ78 effectively controls $\mathrm{Pl}$. viticola in combination with a copper-based fungicide (Puopolo et al. 2014). Based on this evidence, we wanted to see whether its activity could be extended to other plant pathogenic oomycetes. We further investigated the low molecular weight secondary metabolites with anti-oomycete activity released in vitro by $L$. capsici AZ78.

Lysobacter capsici AZ78 has a direct effect on the growth of several oomycetes when tested in dual culture, which leads to a hypothesis of the production of compounds toxic against plant pathogenic oomycetes. We subsequently carried out trials under controlled conditions where L. capsici AZ78 and its own culture filtrates were used for the biological control of $P$. infestans and $P l$. viticola. We proved that the application of $L$. capsici AZ78 cells on tomato leaves strongly reduces tomato late blight, similar to application of the copper-based fungicide Kocide $^{\circledR} 3000$. To the best of our knowledge, this is the first time that a member of the genus 


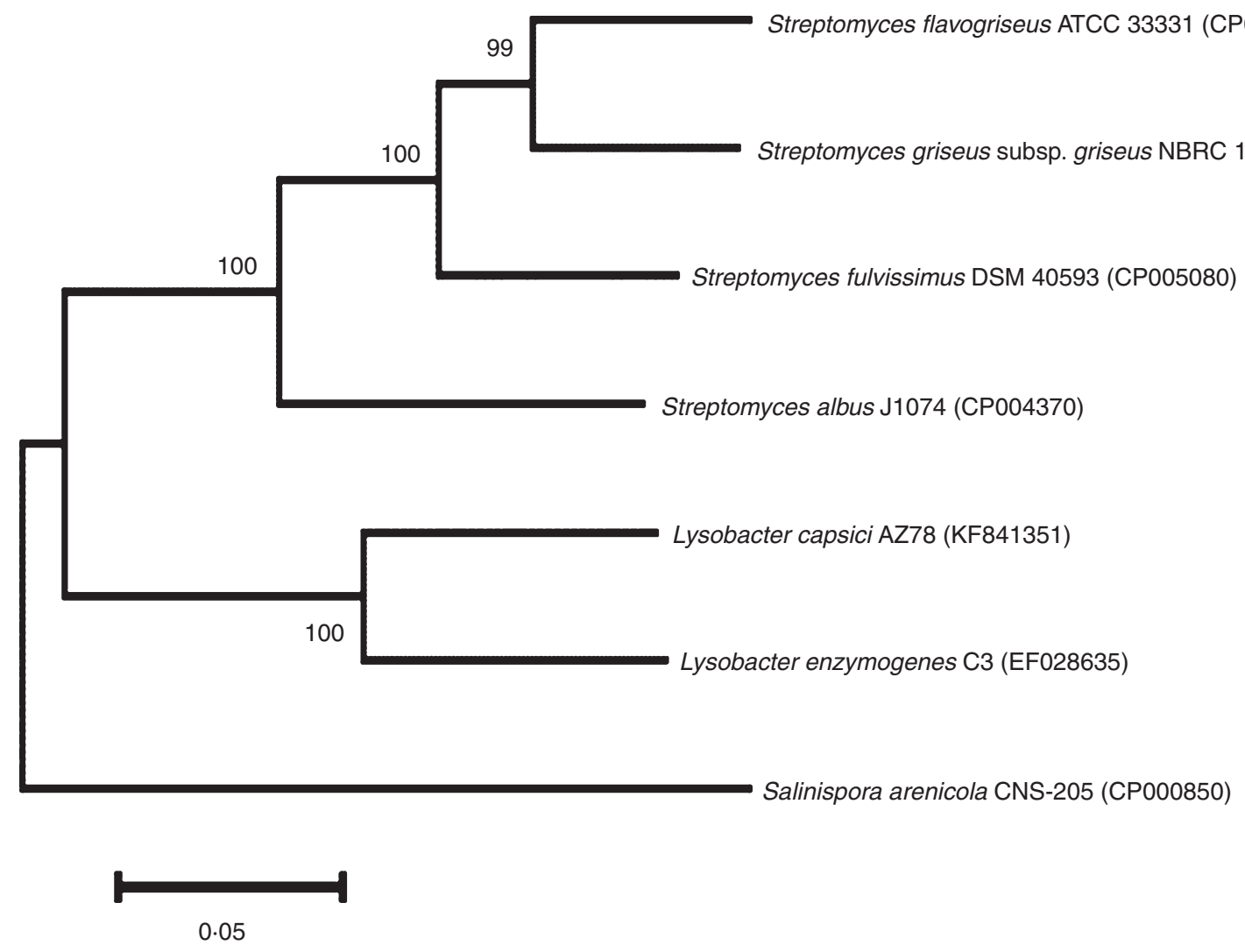

Figure 5 Analysis of sequence identity of a partial region of a gene coding for a hybrid polyketide synthase and nonribosomal peptide synthetase from Lysobacter capsici AZ78. The phylogenetic tree was obtained using the neighbour-joining method, and evolutionary distances were calculated using Kimura's two-parameter model (Kimura 1983). Bootstrap values (Felsenstein 1985) higher than 50 are shown at the branch points.

Lysobacter has been reported to control P. infestans on tomato plants. Previous studies have shown that other Lysobacter strains control soilborne plant pathogenic oomycetes such as Aphanomyces cochlioides and $P y$. aphanidermatum (Nakayama et al. 1999; Folman et al. 2001, 2003, 2004; Islam et al. 2005; ). Recently, Ko et al. (2009) demonstrated that L. antibioticus HS124 effectively protects pepper plants against P. capsici attacks and linked this activity with the production of lytic enzymes (i.e. $\beta$-1,3-glucanase) and an antibiotic compound (4-hydroxyphenylacetic acid). The results obtained in our study thus further strengthen the potential of members of the bacterial genus Lysobacter for biological control of different plant pathogenic oomycetes.

Concurrently, results achieved with the application of L. capsici AZ78 cell-free culture filtrates on plants for the control of P. infestans and Pl. viticola clearly suggested that $L$. capsici AZ78 was producing secondary metabolites that are toxic against both the oomycetes tested. The evidence that a Lysobacter member produces secondary metabolites with anti-oomycete activity is also corroborated by previous studies carried out on Lysobacter sp. SB-K88, L. antibioticus HS124 and L. capsici YC5194 (Homma et al. 1993; Nakayama et al. 1999; Islam et al. 2005; Park et al. 2008; Ko et al. 2009). In particular, Lysobacter sp. SB-K88 synthesizes Xanthobaccin A, B and $\mathrm{C}$, which are highly effective in vitro against Ap. cochlioides, Phytophthora vignae f. sp. adzukicola and Py. ultimum (Nakayama et al. 1999) and in suppressing damping-off of sugar beet caused by Pythium spp. in soil (Homma et al. 1993; Nakayama et al. 1999).

These three macrocyclic lactams were isolated and identified after the screening of chromatographic fractions for their ability to inhibit the mycelial growth of Py. ultimum and Rhizoctonia solani (Nakayama et al. 1999). In our study, on the other hand, we focused our attention on low molecular weight compounds, and the chromatographic fraction groups were evaluated for their toxicity against sporangia of $P$. infestans and Pl. viticola as they represented the primary inoculum source for the trials carried out under controlled conditions. One of the four chromatographic fraction groups was found to be highly toxic against the sporangia of both the plant pathogenic oomycetes. The preliminary NMR investigation, 
using both ${ }^{1} \mathrm{H}$ NMR and ${ }^{13} \mathrm{C}$ NMR spectra, showed that the toxic secondary metabolite was a cyclic dipeptide. On the basis of a comparison of its spectroscopic and optical properties with those already reported in the literature (Tatsuno et al. 1971; Stierle et al. 1988; Jayatilake et al. 1996; Cain et al. 2003), the secondary metabolite present in the chromatographic Fraction B was subsequently identified as the already-known cyclo(L-Pro-L-Tyr), a cyclic dipeptide that belongs to the group of the proline derivatives of 2,5-diketopiperazine, mainly isolated from fungi and bacteria (for a review, see Borthwick 2012).

Up to now, the bioactive products identified and characterized from Lysobacter members mainly belong to the cyclodepsipeptides (lysobactin), cyclic lipodepsipeptides (WAP-8294A2), cephem type $\beta$-lactams (cephabacins) and polycyclic tetramate macrolactam (Xanthobaccin A) families (Ono et al. 1984; O'Sullivan et al. 1988; Kato et al. 1997b; Nakayama et al. 1999; Zhang et al. 2011; Xie et al. 2012). Our study thus provides the first evidence on the production of a 2,5-diketopiperazine from a member of the L. capsici species adding a new compound to the high number of bioactive natural-product families synthesized by Lysobacter genus. We showed moreover, for the first time, that this molecule has toxic effects against the sporangia of both $P$. infestans and Pl. viticola.

Looking at the distribution of 2,5-diketopiperazines within micro-organisms, cyclo(L-Pro-L-Tyr) and its isomer cyclo(D-Pro-L-Tyr) are known to be produced by different bacterial strains belonging mainly to the genus Bacillus and Pseudomonas (Jayatilake et al. 1996; De Rosa et al. 2003; Guo et al. 2007; Nishanth Kumar et al. 2012). Cyclo(L-Pro-L-Tyr) is also produced by Aristabacter necator 679-2 together with two compounds identified as pyrrolnitrin and banegasine (Cain et al. 2003). Moreover, cyclo(L-Pro-L-Tyr) isolated from Pseudomonas aeruginosa PAO1 and Pseudomonas putida WCS358 positively interfered with the quorum sensing system based on the $\mathrm{N}$-acylated L-homoserine lactone signals (Holden et al. 1999; Degrassi et al. 2002). Recently, Ortiz-Castro et al. (2011) showed that the production of cyclo(L-Pro-L-Tyr) in Ps. aeruginosa PAO1 is positively controlled by the LasI quorum sensing system and, moreover, the cyclodipeptide acts as an auxin signal mimic on Arabidopsis thaliana.

Cyclo(L-Pro-L-Tyr) was also isolated from different fungal species such as Alternaria alternata, Fusarium nivale and Leptographium qinlingensis (Tatsuno et al. 1971; Stierle et al. 1988; Li et al. 2012). The cyclo(L-Pro-L-Tyr) compound produced by Al. alternata (also known as maculosin) was found to be toxic against spotted knapweed (Centaurea maculosa), and these evidences lead to the development of a safe and environmentally friendly herbicides against knapweed (Stierle et al. 1988; Bobylev et al. 1996). Interestingly, an Al. alternata endophytic strain isolated from the grapevine produced three proline derivatives of 2,5-diketopiperazines [cyclo(L-Phe-trans-4hydroxy-L-Pro); cyclo(L-Leu-trans-4-hydroxy-L-Pro); and cyclo(L-Ala-trans-4-hydroxy-L-Pro)] that when applied as mixtures was found to be effective in reducing Pl. viticola sporulation (Musetti et al. 2006, 2007). It is worth noting that these results achieved previously and the results reported in our work are indicating that the group of the proline derivatives of 2,5-diketopiperazine are active against $P$. infestans and Pl. viticola; thus, they can also be considered as good candidates for the development of new eco-friendly products that can be applied for a more sustainable control of plant pathogenic oomycetes.

However, on the basis of the results obtained on the application of different doses of cyclo(L-Pro-L-Tyr) on detached tomato leaf, we cannot rule out that other compounds sharing anti-oomycete activity are produced by L. capsici AZ78. These data showed in fact that the cellfree culture filtrates of L. capsici AZ78 were more active than cyclo(L-Pro-L-Tyr) when evaluated at the concentrations found in the growth medium $\left(10 \mu \mathrm{g} \mathrm{ml}^{-1}\right)$. Other potential compounds that can contribute to the control of the plant pathogenic oomycetes tested are the $\beta$-glucanases, already characterized in other Lysobacter members that are known to have effects against plant pathogenic oomycetes (Palumbo et al. 2003, 2005; Ko et al. 2009) and/or by other substances with antibiotic properties. During this work, we detected a genomic region that shared high sequence identity with a hybrid polyketide synthase and nonribosomal peptide synthetase in L. enzymogenes C3 and other bacterial strains belonging mainly to the genus Streptomyces. In Lysobacter, nonribosomal peptide synthetase is responsible for the biosynthesis of several antibiotic compounds such as lysobactin, WAPS8294A2, cephabacin and the dihydromalthophilin heat-stable antifungal factor (HSAF) (Kimura et al. 1995, 1996; Bernhard et al. 1996; Yu et al. 2007; Hou et al. 2011; Zhang et al. 2011). In particular, the nucleotide sequence detected in L. capsici AZ78 showed high sequence identity with the nucleotide region coding for a hybrid polyketide synthase and nonribosomal peptide synthetase deputed to the synthesis of HSAF in L. enzymogenes C3 (Yu et al. 2007). On the basis of this sequence identity, it is reasonable to hypothesize that L. capsici AZ78 may produce some other secondary metabolites active against $P$. infestans and Pl. viticola.

This study provided sound evidences that L. capsici AZ78 can also be applied on tomato for the control of $P$. infestans, enlarging the number of plant pathogenic oomycetes that can be effectively controlled through the application of Lysobacter members. Furthermore, we showed that L. capsici AZ78 produces cyclo(L-Pro-L-Tyr) in vitro and this cyclic dipeptide is toxic against the spo- 
rangia of $P$. infestans and $P l$. viticola. In the next future, the production of this compound will be monitored in planta to assess the role that it plays in the biological control of both the plant pathogenic oomycetes.

However, further investigation will be also aimed to better identify and characterize all the bioactive natural products synthesized by this bacterial strain, and particular attention will be given to the determination of the molecular pathways that are controlling their biosynthesis in order to assess which parameters might be modulated with the final aim of making the future application of L. capsici AZ78 more effective in the field.

\section{Acknowledgements}

The authors thank D. Ress and C. Sicher for technical assistance, D. Melck from the laboratory of Chimica Biomolecolare (CNR, Pozzuoli, Italy) for the NMR spectra and D. Irwin Ianne and M. Reid (Syngenta Jealott's Hill International Research Centre Bracknell, Berkshire, England) for HRESIMS spectra. The research was supported by the EU-project CO-FREE (theme KBBE.2011.1.2-06, grant agreement number 289497).

\section{Conflict of interests}

No conflict of interest declared.

\section{References}

Berger, S. and Braun, S. (2004) 200 and More Basic NMR Experiments: A Practical Course, 1st edn. Weinheim: Wiley-VCH.

Bernhard, F., Demel, G., Soltani, K., Döhren, H.V. and Blinov, V. (1996) Identification of genes encoding for peptide synthetases in the gram-negative bacterium Lysobacter sp. ATCC 53042 and the fungus Cylindrotrichum oligospermum. DNA Seq 6, 319-330.

Bobylev, M.M., Bobyleva, L.I. and Strobel, G.A. (1996) Synthesis and bioactivity of analogs of maculosin, a hostspecific phytotoxin produced by Alternaria alternata on spotted knapweed (Centaurea maculosa). J Agric Food Chem 44, 3960-3964.

Borthwick, A.D. (2012) 2,5-Diketopiperazines: synthesis, reactions, medicinal chemistry, and bioactive natural products. Chem Rev 112, 3641-3716.

Cain, C.C., Lee, D., Waldo, R.H. III, Henry, A.T., Casida, E.J. Jr, Wani, M.C., Wall, M.E., Oberlies, N.H. et al. (2003) Synergistic antimicrobial activity of metabolites produced by a nonobligate bacterial predator. Antimicrob Agents Chemother 47, 2113-2117.

Christensen, P. and Cook, F.D. (1978) Lysobacter, a new genus of nonfruiting, gliding bacteria with a high base ratio. Int J Syst Bacteriol 28, 367-393.
De Rosa, S., Mitova, M. and Tommonaro, G. (2003) Marine bacteria associated with sponge as source of cyclic dipeptides. Biomol Eng 20, 311-316.

Degrassi, G., Aguilar, C., Bosco, M., Zahariev, S., Pongor, S. and Venturi, V. (2002) Plant growth-promoting Pseudomonas putida WCS358 produces and secretes four cyclic dipeptides: cross-talk with quorum sensing bacterial sensors. Curr Microbiol 45, 250-254.

Felsenstein, J. (1985) Confidence limits on phylogenies: an approach using bootstrap. Evolution 39, 783-791.

Folman, L.B., Postma, J. and van Veen, J.A. (2001) Ecophysiological characterization of rhizosphere bacterial communities at different root locations and plant developmental stages of cucumber grown on rockwool. Microb Ecol 42, 586-597.

Folman, L.B., Postma, J. and van Veen, J.A. (2003) Characterization of Lysobacter enzymogenes (Christensen and Cook 1978) strain 3.1T8, a powerful antagonist of fungal diseases of cucumber. Microbiol Res 158, 107-115.

Folman, L.B., De Klein, M.J.E.M., Postma, J. and van Veen, J.A. (2004) Production of antifungal compounds by Lysobacter enzymogenes strain $3.1 \mathrm{~T} 8$ under different conditions in relation to its efficacy as a biocontrol agent of Pythium aphanidermatum in cucumber. Biol Control 31, 145-154.

Fry, W. (2008) Phytophthora infestans: the plant (and R gene) destroyer. Mol Plant Pathol 9, 385-402.

Fry, W. and Goodwin, S. (1997) Re-emergence of potato and tomato late blight in the United States. Plant Dis 81, 1349-1357.

Gessler, C., Pertot, I. and Perazzolli, M. (2011) Plasmopara viticola: a review of knowledge on downy mildew of grapevine and effective disease management. Phytopathol Mediterr 50, 3-44.

Guo, Q., Guo, D., Zhao, B., Xu, J. and Li, R. (2007) Two cyclic dipeptides from Pseudomonas fluorescens GcM5-1A carried by the pine wood nematode and their toxicities to Japanese black pine suspension cells and seedling in vitro. J Nematol 39, 243-247.

Halfeld-Vieira, B.A., Romeiro, R.S., Mounteer, A. and Mizubuti, E.S.G. (2008) Efficiency of phylloplane bacteria in controlling aerial tomato diseases under field conditions. Summa Phytopathol 34, 64-87.

Hayward, A.C., Fegan, N., Fegan, M. and Stirling, G.R. (2010) Stenotrophomonas and Lysobacter: ubiquitous plantassociated gamma-proteobacteria of developing significance in applied microbiology. J Appl Microbiol 108, 756-770.

Holden, M.T.G., Chhabra, S.R., de Nys, R., Stead, P., Bainton, N.J., Hill, P.J., Manefield, M., Kumar, N. et al. (1999) Quorum-sensing cross talk: isolation and chemical characterization of cyclic dipeptides from Pseudomonas aeruginosa and other Gram-negative bacteria. Mol Microbiol 33, 1254-1266. 
Homma, Y., Uchino, H., Kanzawa, K., Nakayama, T. and Sayama, M. (1993) Suppression of sugar beet damping-off and production of antagonistic substances by strains of rhizobacteria. Ann Phytopathol Soc Jpn 59, 282.

Hou, J., Robbel, L. and Marahiel, M.A. (2011) Identification and characterization of the lysobactin biosynthetic gene cluster reveals mechanistic insights into an unusual termination module architecture. Chem Biol 18, 655-664.

Islam, M.T., Hashidoko, Y., Deora, A., Itoi, T. and Tahara, S. (2005) Suppression of damping-off disease in host plants by rhizoplane bacterium Lysobacter sp. strain SB-K88 is linked to plant colonization and antibiosis against soilborne peronosporomycetes. Appl Environ Microbiol 71, 3786-3796.

Jayatilake, G.S., Thornton, M.P., Leonard, A.C., Grimwade, J.E. and Baker, B.J. (1996) Metabolites from an Antarctic sponge-associated bacterium, Pseudomonas aeruginosa. J Nat Prod 59, 293-296.

Kato, M., Mizubuti, E.S., Goodwin, S.B. and Fry, W.E. (1997a) Sensitivity to protectant fungicides and pathogenic fitness of clonal lineages of Phytophthora infestans in the United States. Phytopathology 87, 973-978.

Kato, A., Nakaya, S., Ohashi, Y. and Hirata, H. (1997b) WAP8294A(2), a novel anti-MRSA antibiotic produced by Lysobacter sp. J Am Chem Soc 119, 6680-6681.

Kimura, M. (1983) The Neutral Theory of Molecular Evolution. Cambridge, UK: Cambridge University Press.

Kimura, H., Suzuki, M. and Sumino, Y. (1995) Cloning and expression of the isopenicillin $\mathrm{N}$ synthase gene from Lysobacter lactamgenus YK90. J Ferment Bioeng 80, 118-123.

Kimura, H., Miyashita, H. and Sumino, Y. (1996) Organization and expression in Pseudomonas putida of the gene cluster involved in cephalosporin biosynthesis from Lysobacter lactamgenus YK90. Appl Microbiol Biotechnol 45, 490-501.

Kloepper, J.W., Ryu, C.M. and Zhang, S.A. (2004) Induced systemic resistance and promotion of plant growth by Bacillus spp. Phytopathology 94, 1259-1266.

Ko, H.-S., Jin, R.-D., Krishnan, H.B., Lee, S.-B. and Kim, K.Y. (2009) Biocontrol ability of Lysobacter antibioticus HS124 against Phytophthora blight is mediated by the production of 4-hydroxyphenylacetic acid and several lytic enzymes. Curr Microbiol 59, 608-615.

Kumar, S., Tamura, K. and Nei, M. (2004) MEGA3: integrated software for molecular evolutionary genetics analysis and sequence alignment. Brief Bioinform 5, 150-163.

Lamsal, K., Kim, S.W., Kim, Y.S. and Lee, Y.S. (2013) Biocontrol of late blight and plant growth promotion in tomato using rhizobacterial isolates. J Microbiol Biotechnol 23, 897-904.

Li, X.-J., Gao, J.-M., Chen, H., Zhang, A.-L. and Tang, M. (2012) Toxins from a symbiotic fungus, Leptographium qinlingensis associated with Dendroctonus armandi and their in vitro toxicities to Pinus armandi seedlings. Eur J Plant Pathol 134, 239-247.
Lourenço Júnior, V., Maffia, L.A., Romeiro, R.S. and Mizubuti, E.S.G. (2006) Biocontrol of tomato late blight with the combination of epiphytic antagonists and rhizobacteria. Biol Control 38, 331-340.

Mizubuti, E.S.G., Júnior, V.L. and Forbes, G.A. (2007) Management of late blight with alternative products. Pest Technol 1, 106-116.

Musetti, R., Vecchione, A., Stringher, L., Borselli, S., Zulini, L., Marzani, C., D’Ambrosio, M., di Toppi, L.S. et al. (2006) Inhibition of sporulation and ultrastructural alterations of grapevine downy mildew by the endophytic fungus Alternaria alternata. Phytopathology 96, 689-698.

Musetti, R., Polizzotto, R., Vecchione, A., Borselli, S., Zulini, L., D’Ambrosio, M., di Toppi, L.S. and Pertot, I. (2007) Antifungal activity of diketopiperazines extracted from Alternaria alternata against Plasmopara viticola: an ultrastructural study. Micron 38, 643-650.

Nakayama, T., Homma, Y., Hashidoko, Y., Mizutani, J. and Tahara, S. (1999) Possible role of xanthobaccins produced by Stenotrophomonas sp. strain SB-K88 in suppression of sugar beet damping-off disease. Appl Environ Microbiol 65, 4334-4339.

Nishanth Kumar, S., Mohandas, C., Siji, J.V., Rajasekharan, K.N. and Nambisan, B. (2012) Identification of antimicrobial compound, diketopiperazines, from a Bacillus sp. N strain associated with a rhabditid entomopathogenic nematode against major plant pathogenic fungi. J Appl Microbiol 113, 914-924.

Ono, H., Nozaki, Y., Katayama, N. and Okazaki, H. (1984) Cephabacins, new cephem antibiotics of bacterial origin. I. Discovery and taxonomy of the producing organisms and fermentation. J Antibiot 37, 1528-1535.

Ortiz-Castro, R., Díaz-Pérez, C., Martínez-Trujillo, M., del Río, R.E., Campos-García, J. and López-Bucio, J. (2011) Transkingdom signalling based on bacterial cyclopeptides with auxin activity in plants. Proc Natl Acad Sci USA 108, 7253-7258.

O'Sullivan, J., McCullough, J.E., Tymiak, A.A., Kirsch, D.R., Trejo, W.H. and Principe, P.A. (1988) Lysobactin, a novel antibacterial agent produced by Lysobacter sp. I.

Taxonomy, isolation and partial characterization. $J$ Antibiot 41, 1740-1744.

Palumbo, J.D., Sullivan, R.F. and Kobayashi, D.Y. (2003) Molecular characterization and expression in Escherichia coli of three beta-1,3-glucanase genes from Lysobacter enzymogenes strain N4-7. J Bacteriol 185, 4362-4370.

Palumbo, J.D., Yuen, G.Y., Jochum, C.C., Tatum, K. and Kobayashi, D.Y. (2005) Mutagenesis of beta-1,3-glucanase genes in Lysobacter enzymogenes strain C3 results in reduced biological control activity toward Bipolaris leaf spot of tall fescue and Pythium damping-off of sugar beet. Phytopathology 95, 701-707.

Park, J.H., Kim, R., Aslam, Z., Jeon, C.O. and Chung, Y.R. (2008) Lysobacter capsici sp. nov., with antimicrobial 
activity, isolated from the rhizosphere of pepper, and emended description of the genus Lysobacter. Int J Syst Bacteriol 58, 387-392.

Puopolo, G., Giovannini, O. and Pertot, I. (2014) Lysobacter capsici AZ78 can be combined with copper to effectively control Plasmopara viticola on grapevine. Microbiol Res 169, 633-642.

Raaijmakers, J.M. and Mazzola, M. (2012) Diversity and natural functions of antibiotics produced by beneficial and plant pathogenic bacteria. Annu Rev Phytopathol 50, 403-424.

Saitou, N. and Nei, M. (1987) The neighbor-joining method: a new method for reconstructing phylogenetic trees. $\mathrm{Mol}$ Biol Evol 4, 406-425.

Sergeeva, V., Nair, N., Legendre, L., Darley, E. and SpoonerHart, R. (2002) The use of fluorochromes to determine the effect of chlorine dioxide on survival of Plasmopara viticola on grapevine. Australas Plant Pathol 31, 295-297.

Sharma, K., Butz, A.F. and Finckh, M.R. (2010) Effects of host and pathogen genotypes on inducibility of resistance in tomato (Solanum lycopersicum) to Phytophthora infestans. Plant Pathol 59, 1062-1071.

Stierle, A., Cardellina, J.H. and Strobel, G.A. (1988) Maculosin, a host-specific phytotoxin for spotted knapweed from Alternaria alternata. Proc Natl Acad Sci USA 85, 8008-8013.

Tatsuno, T., Sato, M., Kubota, Y., Kubota, Y. and Tsunoda, H. (1971) Toxicological investigations of metabolic substances of Fusarium nivale. Chem Pharm Bull 19, 1498-1500.

Thompson, J.D., Gibson, T.J., Plewniak, F., Jeanmougin, F. and Higgin, D.G. (1997) The CLUSTAL X Windows interface: flexible strategies for multiple sequence alignment aided by quality analysis tools. Nucleic Acid Res 25, 4876-4882.

Tilcher, R., Wolf, G.A. and Brendel, G. (1994) Effects of microbial antagonists on leaf infestation, sporangia germination and zoospore behaviour of Plasmopara viticola (Berk. \& Curtis) Berl. \& de Toni. Mededelingen Faculteit Landbouwkundige en Toegepaste Biologische Wetenschappen, Universiteit Gent 59, 919-929.

Tilcher, R., Schmidt, C., Lorenz, D. and Wolf, G.A. (2002) About the use of antagonistic bacteria and fungi. In 10th International Conference on Cultivation Technique and Phytopathological Problems in Organic Fruit-Growing and Viticulture. Proceedings to the Conference from 4 th to 7 th February ed. Markus, B., pp. 142-145. Weinsberg/Germany.

Tran, H., Ficke, A., Asiimwe, T., Höfte, M. and Raaijmakers, J.M. (2007) Role of the cyclic lipopeptide massetolide A in biological control of Phytophthora infestans and in colonization of tomato plants by Pseudomonas fluorescens. New Phytol 175, 731-742.

Trouvelot, S., Varnier, A.L., Allègre, M., Mercier, L., Baillieul, F., Arnould, C., Gianinazzi-Pearson, V., Klarzynski, O. et al. (2008) A $\beta-1,3$ glucan sulfate induces resistance in grapevine against Plasmopara viticola through priming of defense responses, including HR-like cell death. Mol Plant Microbe Interact 21, 232-243.
Xie, Y., Wright, S., Shen, Y. and Du, L. (2012) Bioactive natural products from Lysobacter. Nat Prod Rep 29, 1277-1287.

Yan, Z., Reddy, M.S., Ryu, C.-M., McInroy, J.A., Wilson, M. and Kloepper, J.W. (2002) Induced systemic protection against tomato late blight elicited by plant growthpromoting rhizobacteria. Phytopathology 92, 1329-1333.

Yu, F., Zaleta-Rivera, K., Zhu, X., Huffman, J., Millet, J.C., Harris, S.D., Yuen, G., Li, X.-C. et al. (2007) Structure and biosynthesis of heat-stable antifungal factor (HSAF), a broad-spectrum antimycotic with a novel mode of action. Antimicrob Agents Chemother 51, 64-72.

Zhang, W., Li, Y., Qian, G., Wang, Y., Chen, H., Li, Y.Z., Liu, F., Shen, Y. et al. (2011) Identification and characterization of the anti-methicillin-resistant Staphylococcus aureus WAP-8294A2 biosynthetic gene cluster from Lysobacter enzymogenes OH11. Antimicrob Agents Chemother 55, 5581-5589.

\section{Supporting Information}

Additional Supporting Information may be found in the online version of this article:

Table S1 Disease incidence (percentage of symptomatic leaves) of Phytophthora infestans and Plasmopara viticola on tomato and grapevine plants, treated Lysobacter capsici AZ78 cells and its culture filtrate (c.f.).

Figure S1 Effect of the four organic fraction of Lysobacter capsici AZ78 culture filtrates extracted with ethyl acetate on viability of sporangia of Phytophthora infestans (a) and Plasmopara viticola (b).

Data S1 Identification of cyclo(L-Pro-L-Tyr).

Figure S2 ${ }^{13} \mathrm{C}$ NMR spectrum of cyclo(L-Pro-L-Tyr) was recorded at $600 \mathrm{MHz}$ in monodeuterated chloroform.

Figure S3 Correlation spectroscopy (COSY) NMR spectrum of cyclo(L-Pro-L-Tyr) was recorded at $600 \mathrm{MHz}$ in monodeuterated chloroform.

Figure S4 Heteronuclear single quantum coherence (HSQC) NMR spectrum of cyclo(L-Pro-L-Tyr) was recorded at $600 \mathrm{MHz}$ in monodeuterated chloroform.

Figure S5 Nuclear overhauser enhancement spectroscopy (NOESY) NMR spectrum of cyclo(L-Pro-L-Tyr) was recorded at $600 \mathrm{MHz}$ in monodeuterated chloroform.

Figure S6 Heteronuclear multiple bond correlation (HMBC) NMR spectrum of cyclo(L-Pro-L-Tyr) was recorded at $600 \mathrm{MHz}$ in monodeuterated chloroform.

Figure S7 Liquid chromatography/high resolution (HR) electrospray ionization mass spectroscopy (ESI MS) spectrum of cyclo(L-Pro-L-Tyr).

Figure S8 Dose effect of cyclo(L-Pro-L-Tyr) on Phytophthora infestans disease incidence on detached tomato leaves. 